\title{
Association between change in physician remuneration and use of peritoneal dialysis: a population-based cohort analysis
}

\author{
Aaron J. Trachtenberg MD DPhil, Amity E. Quinn PhD, Zhihai Ma MSc, Scott Klarenbach MSc, \\ Brenda Hemmelgarn MD PhD, Marcello Tonelli MD SM, Peter Faris PhD, Robert Weaver MSc, \\ Flora Au MEc, Jianguo Zhang MSc, Braden Manns MD MSc
}

\section{Abstract}

Background: Health care payers are interested in policy-level interventions to increase peritoneal dialysis use in end-stage renal disease. We examined whether increases in physician remuneration for peritoneal dialysis were associated with greater peritoneal dialysis use.

Methods: We studied a cohort of patients in Alberta who started long-term dialysis with at least 90 days of preceding nephrologist care between Jan. 1, 2001, and Dec. 31, 2014. We compared peritoneal dialysis use 90 days after dialysis initiation in patients cared for by fee-for-service nephrologists and those cared for by salaried nephrologists before and after weekly peritoneal dialysis remuneration increased from $\$ 0$ to $\$ 32$ (fee change 1, Apr. 1, 2002), $\$ 49$ to $\$ 71$ (fee change 2, Apr. 1, 2007), and $\$ 71$ to $\$ 135$ (fee change 3 , Apr. 1, 2009). Remuneration for peritoneal dialysis remained less than hemodialysis until fee change 3 . We performed a patient-level differences-in-differences logistic regression, adjusted for demographic characteristics and comorbidities, as well as an unadjusted interrupted time-series analysis of monthly outcome data.

Results: Our cohort included 4262 patients. There was no statistical evidence of a difference in the adjusted differences-indifferences estimator following fee change 1 (0.89, 95\% confidence interval [ $\mathrm{Cl}]$ 0.44-1.81), 2 (1.15, 95\% Cl 0.73-1.83), or 3 (1.52, $95 \% \mathrm{Cl}$ 0.96-2.40). There was no significant difference in the immediate change or the trend over time in peritoneal dialysis use between fee-for-service and salaried groups following any of the fee changes in the interrupted time-series analysis.

Interpretation: We identified no statistical evidence of an increase in peritoneal dialysis use following increased fee-for-service remuneration for peritoneal dialysis. It remains unclear what role, if any, physician payment plays in selection of dialysis modality.

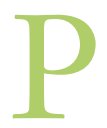

eritoneal dialysis (performed at home) is associated with similar overall survival and at least equivalent quality of life compared to in-centre hemodialysis, ${ }^{1-5}$ and is associated with much lower health care costs. ${ }^{6}$ However, peritoneal dialysis is used much less frequently than hemodialysis. ${ }^{7}$ In the United States, less than $10 \%$ of patients with incident end-stage renal disease initiate dialysis with peritoneal dialysis, ${ }^{8}$ whereas in Canada, $20 \%-25 \%$ of patients do. ${ }^{9}$

Internationally, health care policies ranging from strict "peritoneal-dialysis-first" approaches to financial incentives to dialysis facilities that encourage greater peritoneal dialysis use $\mathrm{e}^{10,11}$ aim to increase peritoneal dialysis use. For example, the US adopted a prospective payment system in 2011 providing equal payment regardless of dialysis modality (thus reimbursing peritoneal dialysis higher than its cost), which was associated with a $30 \%-$ $40 \%$ relative increase in incident peritoneal dialysis use. $^{8,12-14}$ This together with other research ${ }^{11,15,16}$ suggests that facility-level reimbursement can affect peritoneal dialysis use, particularly in profit-driven systems.

Physicians may also respond to economic incentives, although there has been less research examining the effect of physician-level dialysis remuneration on the type of dialysis initiated. It is possible that low physician payment for peritoneal dialysis may be a barrier to its use. Studies have shown that increased payment for in-centre hemodialysis compared to peritoneal dialysis was associated with a reduction in

Competing interests: Braden Manns held an unrestricted grant from Baxter from 2014 to 2017, outside the submitted work. No other competing interests were declared.

This article has been peer reviewed.

Correspondence to: Braden Manns, Braden.Manns@ albertahealthservices.ca

CMAJ Open 2020. DOI:10.9778/cmajo.20190132 
peritoneal dialysis use ${ }^{17}$ and that changing from a fee-forservice remuneration system (which paid more for hemodialysis than peritoneal dialysis) to a capitation system (which paid physicians equally for peritoneal dialysis and hemodialysis) may have slowed the decline in peritoneal dialysis use. ${ }^{18}$

We used a natural experiment in which remuneration for peritoneal dialysis changed over a 15-year period in Alberta to examine the association between increasing payment for peritoneal dialysis and peritoneal dialysis use.

\section{Methods}

\section{Setting}

In this population-based analysis, we examined changes in a provincially determined fee schedule during 2 discrete periods: Jan. 1, 2001-Mar. 31, 2004 and Apr. 1, 2005-Dec. 31, 2014 (Figure 1). Patients cared for by fee-for-service nephrologists were the intervention group, and those cared for by salaried nephrologists (among whom there was no change in payment over time) were the comparison group. Including salaried nephrologists allowed us to control for local trends in peritoneal dialysis not related to fee changes, as the behaviour of salaried physicians should not have been influenced directly by fee schedule changes.

Patients receiving outpatient care in preparation for dialysis are cared for by a primary nephrologist. We defined a patient's "most responsible nephrologist" as the nephrologist with the highest number of outpatient claims in the 90-365 days before dialysis initiation. The payment model for each patient's assigned nephrologist was determined at dialysis initiation.

\section{Study period 1 (Jan. 1, 2001-Mar. 31, 2004)}

Before Apr. 1, 2002, there was no billing code for peritoneal dialysis. Fee change 1 occurred on Apr. 1, 2002, introducing a weekly fee remunerating fee-for-service nephrologists $\$ 32.16$ per patient receiving peritoneal dialysis. There were 21 feefor-service nephrologists across Alberta and 16 salaried nephrologists in 1 urban centre as of 2001.
Exclusion period (Apr. 1, 2004-Mar. 31, 2005)

In April 2004, the salary program expanded to another urban centre, and the weekly fee was increased. Owing to simultaneous interventions, as well as the change in payment models for nephrologists, we excluded patients who started dialysis between Apr. 1, 2004, and Mar. 31, 2005 from the statistical analysis.

\section{Study period 2 (Apr. 1, 2005-Dec. 31, 2014)}

At the start of study period 2, the fee for peritoneal dialysis was $\$ 49.15$ per week. Fee change 2 occurred on Apr. 1, 2007, when the fee increased to $\$ 70.94$ per week. Fee change 3 occurred on Apr. 1, 2009, when a single weekly fee code was introduced for all patients receiving dialysis (hemodialysis or peritoneal dialysis) at $\$ 135$ per week. There were 20 fee-forservice nephrologists across Alberta and 46 salaried nephrologists practising in 2 large urban centres as of 2005 .

\section{Data sources}

We used data from the Northern and Southern Alberta Renal Program registries (which include clinical information for all patients receiving dialysis in Alberta and those with advanced chronic kidney disease seeing nephrologists ${ }^{19}$ ) along with data from the Alberta Kidney Disease Network ${ }^{20}$ to identify patients starting long-term dialysis or receiving a renal transplant, the date of dialysis initiation and the dialysis modality. We obtained patient demographic and clinical details, and nephrologists' remuneration method and other characteristics from Alberta Health administrative data. ${ }^{20}$

\section{Study population}

Eligible participants were all adult (age $\geq 18 \mathrm{yr}$ ) Albertans who started long-term dialysis between Jan. 1, 2001, and Dec. 31, 2014. Patients who recovered kidney function within 90 days of starting dialysis were excluded, but patients were included if the dialysis was intended to be long-term but they died or received a kidney transplant within 90 days. We included those who died or received a transplant to be consistent with intention-to-treat-principles and to reduce any bias that

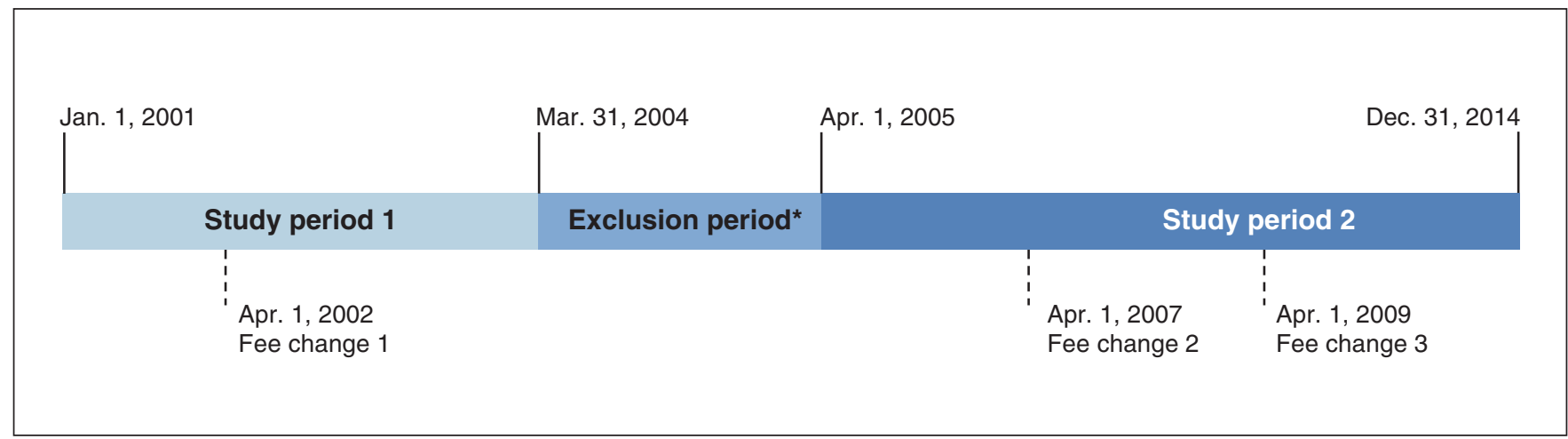

Figure 1: Division of the entire study period for analysis purposes. Fee change 1 = introduction of weekly billing code for patients receiving peritoneal dialysis at $\$ 32.16$. Fee change $2=$ increase in weekly billing code for patients receiving peritoneal dialysis from $\$ 49.15$ to $\$ 70.94$. Fee change 3 = introduction of weekly billing code for all dialysis modalities at $\$ 135$. Note that, during the exclusion period, the weekly billing code for patients receiving peritoneal dialysis was increased from $\$ 32.16$ to $\$ 49.15$, but we did not analyze this increase owing to the simultaneous expansion of the salaried program. *Patients who started dialysis during this period were excluded. 
might occur if mortality was different between fee-for-service and salaried nephrologists. We used a 90-day period to allow for those who may have started hemodialysis acutely to transfer to peritoneal dialysis. ${ }^{21} \mathrm{We}$ also excluded patients who had received a renal transplant before Jan. 1, 2001; had their first nephrology visit within 90 days before starting dialysis, since there is little opportunity for physician-patient interaction or modality education, and, under these circumstances, most patients receive hemodialysis $;^{19}$ had a primary nephrologist who could not prescribe peritoneal dialysis because of the hospital he or she was affiliated with; and had missing dialysis information at 90 days.

\section{Outcomes}

The primary outcome was peritoneal dialysis use 90 days after dialysis initiation, as identified with the Northern and Southern Alberta Renal Program registries. ${ }^{19}$ All patients receiving hemodialysis or a kidney transplant or who died within 90 days were recorded as not using peritoneal dialysis. (For the interrupted time-series analysis described in Appendix 1, available at www.cmajopen.ca/content/8/1/E96/suppl/DC1, the outcome was the monthly proportion of patients starting dialysis who were using peritoneal dialysis at $90 \mathrm{~d}$ ).

We defined patient and physician variables at the patient level on the date of dialysis initiation. Patient variables included age, sex and chronic comorbid conditions identified by applying previously validated administrative data algorithms. ${ }^{22}$ We used residential postal code to measure the distance to the closest hemodialysis facility and the closest peritoneal dialysis training centre, and to determine median neighbourhood household income quintile as a marker of socioeconomic status. ${ }^{20}$ To determine neighbourhood income for an individual patient, we used a demographic registry file to identify a patient's postal code nearest to their dialysis start date and then matched the patient's postal code to the corresponding neighbourhood income quintile defined in the Canadian census nearest to the patient's dialysis start date (e.g., 2001, 2006) or in the 2011 National Household Survey (because the long-form census was not conducted in 2011). ${ }^{23-26}$ Physician-level variables included clinical workload, years billing since 1994 and practice location, all defined by means of claims data.

\section{Statistical analysis}

We determined differences in characteristics between groups and within-group differences before and after fee changes with the $t$ test or 1-way analysis of variance for continuous variables and the $\chi^{2}$ test for categorical variables (Fisher exact test was used when $\geq 20 \%$ of cells had an expected value $<5$ ). For each study period, we plotted the monthly proportion of patients starting dialysis who were using peritoneal dialysis at 90 days for the fee-for-service and salaried groups.

We performed individual patient-level analysis using a difference-in-differences logistic regression with a generalized estimating equation model. Generalized estimating equation accounts for inherent correlation in the data due to clustering of patients at the physician level. ${ }^{27}$ Study period 2 was broken into 2 subperiods for the difference-in-differences approach: Apr. 1, 2005-Mar. 31, 2009 to assess fee change 2, and Apr. 1, 2007-Dec. 31, 2014 to assess fee change 3. We report the difference-in-differences estimator with and without adjustment for age, sex, income quintile, comorbidities, dialysis initiation as inpatient, distance between patient postal code and nearest hemodialysis facility, and distance between patient postal code and nearest peritoneal dialysis training centre. The differences-in-differences estimator is the odds ratio for peritoneal dialysis use in the fee-for-service group after versus before a fee change, divided by the odds ratio for peritoneal dialysis use in the salaried group after versus before a fee change. A difference-in-differences estimator greater than 1 implies that there was a greater increase in the odds of peritoneal dialysis use for a patient in the fee-forservice group than for a patient in the salaried group following a fee change. A differences-in-differences estimator less than 1 implies the opposite.

In secondary analyses, we conducted an interrupted timeseries analysis using unadjusted segmented linear regression. Since it is possible that patients might have started dialysis with peritoneal dialysis but transferred to hemodialysis within the first 90 days, we performed a sensitivity analysis to examine the impact of changing the outcome from peritoneal dialysis use at 90 days to peritoneal dialysis use on the day patients initiated long-term dialysis. We also completed a sensitivity analysis repeating the interrupted time-series analysis using quarterly rather than monthly periods. We performed all analyses using SAS 9.4 (SAS Institute) and Stata 14.2 (StataCorp).

\section{Ethics approval}

Ethics approval was obtained from the Conjoint Health Research Ethics Board of the University of Calgary.

\section{Resullts}

Our cohort included 4262 patients who started long-term dialysis in Alberta between 2001 and 2014, all of whom received care from a nephrologist for at least 90 days before starting dialysis (Figure 2). There were 879 patients in study period 1 and 3120 patients in study period 2; 263 patients started dialysis during the 1-year exclusion period.

Overall, the cohorts of patients seen by fee-for-service and salaried nephrologists were similar, as were the groups seen before and after the fee changes, with only small differences noted across certain baseline characteristics (Tables 1 and 2). The characteristics of fee-for-service and salaried nephrologists were similar before and after the fee changes (within payment model groups), but there were significant differences in clinical workload and practice location between fee-forservice and salaried nephrologists in each period (Appendix 1, Supplementary Tables S1 and S2).

Figure 3 shows the proportion of patients using peritoneal dialysis at 90 days each month over time. In study period 1, 42 patients $(21.3 \%$, 95\% CI $15.4 \%-27.3 \%)$ in the fee-for-service 


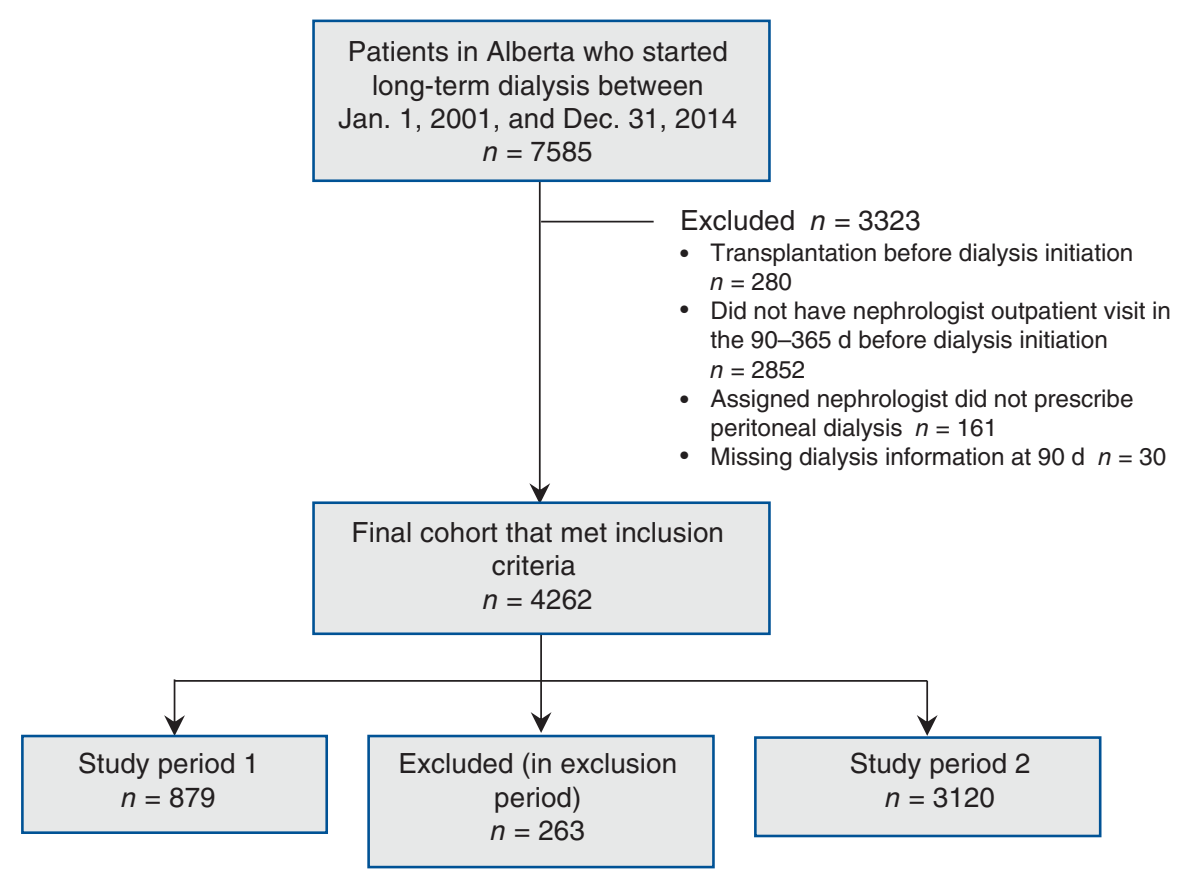

Figure 2: Flow diagram showing participant selection.

group were receiving peritoneal dialysis 90 days before fee change 1 , and 58 patients $(17.9 \%, 95 \%$ CI $13.5 \%-22.2 \%)$ after; the corresponding values for the salaried group were $27(21.8 \%$, 95\% CI 14.1\%-29.4\%) and 54 (23.2\%, 95\% CI 17.5\%-28.8\%). In study period 2,72 patients $(22.8 \%, 95 \%$ CI $18.0 \%-27.6 \%)$ in the fee-for-service group were using peritoneal dialysis 90 days before fee change 2, 76 patients (22.7\%, 95\% CI 18.1\%-27.3\%) between fee changes 2 and 3, and 277 patients $(26.0 \%, 95 \%$ CI $23.3 \%-28.7 \%$ ) after fee change 3 . The corresponding values for the salaried group were 90 (32.3\%, 95\% CI 27.6\%-37.9\%), 70 $(29.7 \%, 95 \%$ CI $23.6 \%-35.7 \%)$ and $249(28.0 \%, 95 \%$ CI $25.0 \%-31.0 \%)$.

The $95 \%$ CIs for all difference-in-differences estimators reported included 0 , which indicates there was no statistically significant difference in the effect of a fee change on peritoneal dialysis use at the individual patient level between the fee-for-service and salaried groups, whether adjusting for covariates or not (Table 3 ).

\section{Sensitivity analysis}

When we used peritoneal dialysis use on the day patients initiated long-term dialysis as the outcome, interrupted time-series results remained unchanged, with no significant effect of any fee change on the aggregated monthly proportion of patients using peritoneal dialysis. At the individual patient level, the differences-in-differences estimators from the generalized estimating equation logistic regression remained nonsignificant for the effects of fee changes 1 and 2 but became significant for the effect of fee change 3, both unadjusted (differences-in-differences estimator 1.42, 95\%
CI 1.01-2.01) and adjusted (differences-in-differences estimator $1.65,95 \%$ CI 1.12-2.43) for covariates.

When the interrupted time-series analysis was repeated using quarterly rather than monthly intervals, the results were unchanged.

\section{Interpretation}

There was no statistical evidence of an increase in the use of peritoneal dialysis 90 days following the implementation of fee changes that raised nephrologist remuneration for peritoneal dialysis. Our results were the same with 2 complementary quasi-experimental methodologies: an individual patient-level differences-in-differences logistic regression model, which accounted for potential clustering of patient outcomes at the physician level, and controlled for clinical and demographic covariates, and an aggregate-level interrupted time-series analysis, which allowed for visual representation and statistical analysis of the detailed trends in peritoneal dialysis use over time (Figure 3, Appendix 1).

Our results are generally consistent with those of previous studies showing that physician-level remuneration likely has little, if any, impact on use of peritoneal dialysis. ${ }^{17,18}$ Although Erickson and colleagues ${ }^{17}$ found a decrease in peritoneal dialysis use in the US after a switch from capitation to tiered feefor-service, the magnitude was small (absolute difference of $0.7 \%$ over $3 \mathrm{yr}$ ) and may not be meaningful from a policy perspective. ${ }^{17}$ Importantly, in our work and related research, ${ }^{17,18}$ the amount paid for care of a patient receiving peritoneal dialysis never exceeded that of a patient receiving hemodialysis. 


\begin{tabular}{|c|c|c|c|c|}
\hline \multirow[b]{2}{*}{ Characteristic } & \multicolumn{2}{|c|}{ Fee-for-service, no. (\%) of patients $\dagger$} & \multicolumn{2}{|c|}{ Salaried, no. (\%) of patients† } \\
\hline & $\begin{array}{l}\text { Before fee } \\
\text { change } 1 \\
n=197\end{array}$ & $\begin{array}{l}\text { After fee } \\
\text { change } 1 \\
n=325\end{array}$ & $\begin{array}{c}\text { Before fee } \\
\text { change } 1 \\
n=124\end{array}$ & $\begin{array}{l}\text { After fee } \\
\text { change } 1 \\
n=233\end{array}$ \\
\hline No. of months & 15 & 24 & 15 & 24 \\
\hline Age, yr, mean \pm SD $\ddagger$ & $62.6 \pm 15.9$ & $64.6 \pm 15.7$ & $62.7 \pm 15.8$ & $59.5 \pm 16.1$ \\
\hline Female sex & $88(44.7)$ & $154(47.4)$ & $51(41.1)$ & $98(42.1)$ \\
\hline \multicolumn{5}{|l|}{ Income quintile§ } \\
\hline 1 (lowest) & $53(26.9)$ & $72(22.2)$ & $34(27.4)$ & $64(27.5)$ \\
\hline 2 & $36(18.3)$ & $73(22.5)$ & $27(21.8)$ & $41(17.6)$ \\
\hline 3 & $33(16.8)$ & $60(18.5)$ & $17(13.7)$ & $49(21.0)$ \\
\hline 4 & $30(15.2)$ & $46(14.2)$ & $25(20.2)$ & $38(16.3)$ \\
\hline 5 (highest) & 38 (19.3) & $54(16.6)$ & $14(11.3)$ & $28(12.0)$ \\
\hline Unknownף & $7(3.6)$ & $20(6.2)$ & $7(5.6)$ & $13(5.6)$ \\
\hline \multicolumn{5}{|l|}{ Comorbidities } \\
\hline Alcohol use disorder & $14(7.1)$ & $15(4.6)$ & $3(2.4)$ & $14(6.0)$ \\
\hline Cancer, nonmetastatic & $14(7.1)$ & $16(4.9)$ & $5(4.0)$ & $11(4.7)$ \\
\hline Chronic heart failure $\ddagger$ & $79(40.1)$ & $148(45.5)$ & $40(32.3)$ & $82(35.2)$ \\
\hline Chronic pulmonary diseaseł & $45(22.8)$ & $113(34.8)^{\star \star}$ & $37(29.8)$ & $62(26.6)$ \\
\hline Dementia & $4(2.0)$ & $10(3.1)$ & $4(3.2)$ & $7(3.0)$ \\
\hline Diabetes & $115(58.4)$ & $183(56.3)$ & $74(59.7)$ & $130(55.8)$ \\
\hline Myocardial infarction & $15(7.6)$ & $31(9.5)$ & $10(8.1)$ & $21(9.0)$ \\
\hline Peripheral vascular disease & $21(10.7)$ & $38(11.7)$ & $6(4.8)$ & $19(8.2)$ \\
\hline Stroke/transient ischemic attack & $36(18.3)$ & $71(21.8)$ & $24(19.4)$ & $40(17.2)$ \\
\hline Dialysis initiation as inpatient & $62(31.5)$ & $88(27.1)$ & $39(31.4)$ & $64(27.5)$ \\
\hline \multicolumn{5}{|l|}{$\begin{array}{l}\text { Distance between patient postal } \\
\text { code and nearest hemodialysis } \\
\text { facility, km‡†† }\end{array}$} \\
\hline$<50$ & $166(84.3)$ & $290(89.2)$ & $102(82.3)$ & $192(82.4)$ \\
\hline $50-150$ & $31(15.7)$ & $33(10.2)$ & $17(13.7)$ & $29(12.4)$ \\
\hline$>150$ & $0(0.0)$ & $2(0.6)$ & $5(4.0)$ & $12(5.2)$ \\
\hline $\begin{array}{l}\text { Distance between patient postal } \\
\text { code and nearest peritoneal } \\
\text { dialysis training centre, km¥†† }\end{array}$ & & ** & & \\
\hline$<50$ & $134(68.0)$ & 249 (76.6) & $80(64.5)$ & $138(59.2)$ \\
\hline $50-150$ & $45(22.8)$ & 64 (19.7) & $18(14.5)$ & $41(17.6)$ \\
\hline$>150$ & $18(9.1)$ & $12(3.7)$ & $26(21.0)$ & $54(23.2)$ \\
\hline \multicolumn{5}{|c|}{$\begin{array}{l}\text { Note: } \mathrm{SD}=\text { standard deviation. } \\
\text { *All covariates defined based on the date of dialysis initiation. } \chi^{2} \text { test was used for categorical variables (Fisher exact test when } \geq 20 \% \text { of } \\
\text { cells had an expected value }<5 \text { ), and } 2 \text {-sided } 2 \text {-sample } t \text { test for continuous variables. } \\
\text { EExcept where noted otherwise. } \\
\text { FSignificant at } p<0.05 \text { for difference between fee-for-service and salaried groups after policy change. } \\
\text { §Estimated with the use of the postal code. } \\
\text { १These patients had postal codes without neighbourhood income data available. } \\
\star^{*} \text { Significant at } p<0.05 \text { for within-group difference before and after fee change. } \\
\text { tSignificant at } p<0.05 \text { for difference between fee-for-service and salaried groups before policy change. }\end{array}$} \\
\hline
\end{tabular}

In a sensitivity analysis, we found a significant differences-in-differences effect of fee change 3 on peritoneal dialysis use at day 90 of greater than 1, which suggests that peritoneal dialysis use increased more in patients assigned to fee-for-service nephrologists after the equalization of peritoneal dialysis and hemodialysis remuneration than it 


\begin{tabular}{|c|c|c|c|c|c|c|}
\hline \multirow[b]{2}{*}{ Characteristic } & \multicolumn{3}{|c|}{ Fee-for-service, no. (\%) of patients† } & \multicolumn{3}{|c|}{ Salaried, no. (\%) of patients† } \\
\hline & $\begin{array}{l}\text { Before fee } \\
\text { change } 2 \\
n=316\end{array}$ & $\begin{array}{l}\text { Between fee } \\
\text { changes } 2 \\
\text { and } 3 \\
n=335\end{array}$ & $\begin{array}{l}\text { After fee } \\
\text { change } 3 \\
n=1065\end{array}$ & $\begin{array}{l}\text { Before fee } \\
\text { change } 2 \\
n=279\end{array}$ & $\begin{array}{c}\text { Between fee } \\
\text { changes } 2 \\
\text { and } 3 \\
n=236\end{array}$ & $\begin{array}{l}\text { After fee } \\
\text { change } 3 \\
n=889\end{array}$ \\
\hline No. of months & 24 & 24 & 69 & 24 & 24 & 69 \\
\hline Age, yr, mean \pm SD $\ddagger$ & $64.1 \pm 15.5$ & $62.91 \pm 15.7$ & $63.4 \pm 14.6$ & $63.1 \pm 15.1$ & $63.2 \pm 14.1$ & $61.3 \pm 15.6$ \\
\hline Female sex & $132(41.8)$ & $116(34.6)$ & $424(39.8)$ & $111(39.8)$ & $84(35.6)$ & $333(37.5)$ \\
\hline Income quintile§ & & & १ & & & \\
\hline 1 (lowest) & $85(26.9)$ & $87(26.0)$ & $300(28.2)$ & $80(28.7)$ & $56(23.7)$ & $238(26.8)$ \\
\hline 2 & $73(23.1)$ & $78(23.3)$ & $235(22.1)$ & $60(21.5)$ & $57(24.2)$ & $208(23.4)$ \\
\hline 3 & $62(19.6)$ & $66(19.7)$ & $187(17.6)$ & $41(14.7)$ & $42(17.8)$ & $153(17.2)$ \\
\hline 4 & $53(16.8)$ & $60(17.9)$ & $154(14.5)$ & $53(19.0)$ & $41(17.4)$ & $133(15.0)$ \\
\hline 5 (highest) & $43(13.6)$ & $42(12.5)$ & $135(12.7)$ & $45(16.1)$ & $36(15.2)$ & $124(13.9)$ \\
\hline Unknown** & $0(0.0)$ & $2(0.6)$ & $54(5.1)$ & $0(0.0)$ & $4(1.7)$ & $33(3.7)$ \\
\hline \multicolumn{7}{|l|}{ Comorbidities } \\
\hline Alcohol use disorder & $19(6.0)$ & $22(6.6)$ & $69(6.5)$ & $113(40.5)$ & $21(8.9)$ & $68(7.6)$ \\
\hline Cancer, nonmetastatic & $14(4.4)$ & $15(4.5)$ & $63(5.9)$ & $11(3.9)$ & $16(6.8)$ & $65(7.3)$ \\
\hline Chronic heart failure†† & $150(47.5)$ & $147(43.9)$ & $447(42.0)$ & $100(35.8)$ & $93(39.4)$ & $351(39.5)$ \\
\hline Chronic pulmonary disease & $101(32.0)$ & $105(31.3)$ & $328(30.8)$ & $85(30.5)$ & $96(40.7)$ & $265(29.8)$ \\
\hline Dementia & $14(4.4)$ & $15(4.5)$ & $43(4.0)$ & $6(2.2)$ & $8(3.4)$ & $38(4.3)$ \\
\hline Diabetes & $185(58.5)$ & $201(60.0)$ & 760 (71.4)ף & $151(54.1)$ & $139(58.9)$ & 565 (63.6)ף \\
\hline Myocardial infarction & $42(13.3)$ & $53(15.8)$ & $167(15.7)$ & $33(11.8)$ & $46(19.5)$ & $140(15.7)$ \\
\hline Peripheral vascular disease & $26(8.2)$ & $34(10.1)$ & $108(10.1)$ & $24(8.6)$ & $28(11.9)$ & $105(11.8)$ \\
\hline Stroke/transient ischemic attack & $69(21.8)$ & $65(19.4)$ & $264(24.8)$ & $55(19.7)$ & $52(22.0)$ & $211(23.7)$ \\
\hline Dialysis initiation as inpatientł†† & $126(39.9)$ & $130(38.8)$ & $440(41.3)$ & 89 (31.9) & $81(34.3)$ & $320(36.0)$ \\
\hline \multicolumn{7}{|l|}{$\begin{array}{l}\text { Distance between patient postal code } \\
\text { and nearest hemodialysis facility, km }\end{array}$} \\
\hline$<50$ & $286(90.5)$ & $299(89.2)$ & 957 (89.9) & $239(85.7)$ & $209(88.6)$ & $776(87.3)$ \\
\hline $50-150$ & $28(8.9)$ & $29(8.7)$ & $89(8.4)$ & 37 (13.3) & $23(9.7)$ & $102(11.5)$ \\
\hline$>150$ & $2(0.6)$ & $7(2.1)$ & $19(1.8)$ & $3(1.1)$ & $4(1.7)$ & $11(1.2)$ \\
\hline $\begin{array}{l}\text { Distance between patient postal code } \\
\text { and nearest peritoneal dialysis } \\
\text { training centre, km†††ł‡ }\end{array}$ & & & १ & & & \\
\hline$<50$ & $229(72.5)$ & $216(64.5)$ & $790(74.2)$ & $199(71.3)$ & $164(69.5)$ & $645(72.6)$ \\
\hline $50-150$ & $66(20.9)$ & $84(25.1)$ & $193(18.1)$ & $34(12.2)$ & $35(14.8)$ & $99(11.1)$ \\
\hline$>150$ & $21(6.6)$ & $35(10.4)$ & $82(7.7)$ & $46(16.5)$ & $37(15.7)$ & $145(16.3)$ \\
\hline \multicolumn{7}{|c|}{ 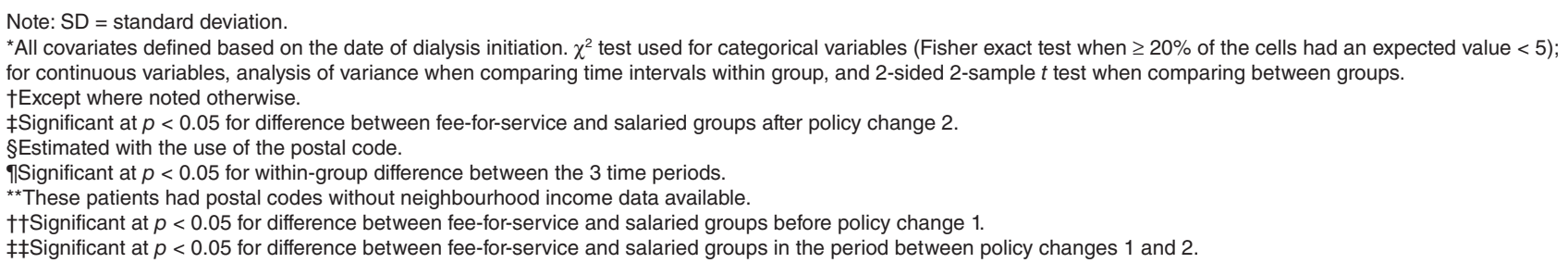 } \\
\hline
\end{tabular}

did in patients assigned to salaried nephrologists. Although the effect size was small and the complementary interrupted time-series analysis was nonsignificant, this may suggest that the effects of remuneration on peritoneal dialysis use appear only when payment is at least equal. It remains unclear whether paying physicians more for peritoneal dialysis than for hemodialysis has a meaningful effect on dialysis modality selection. 


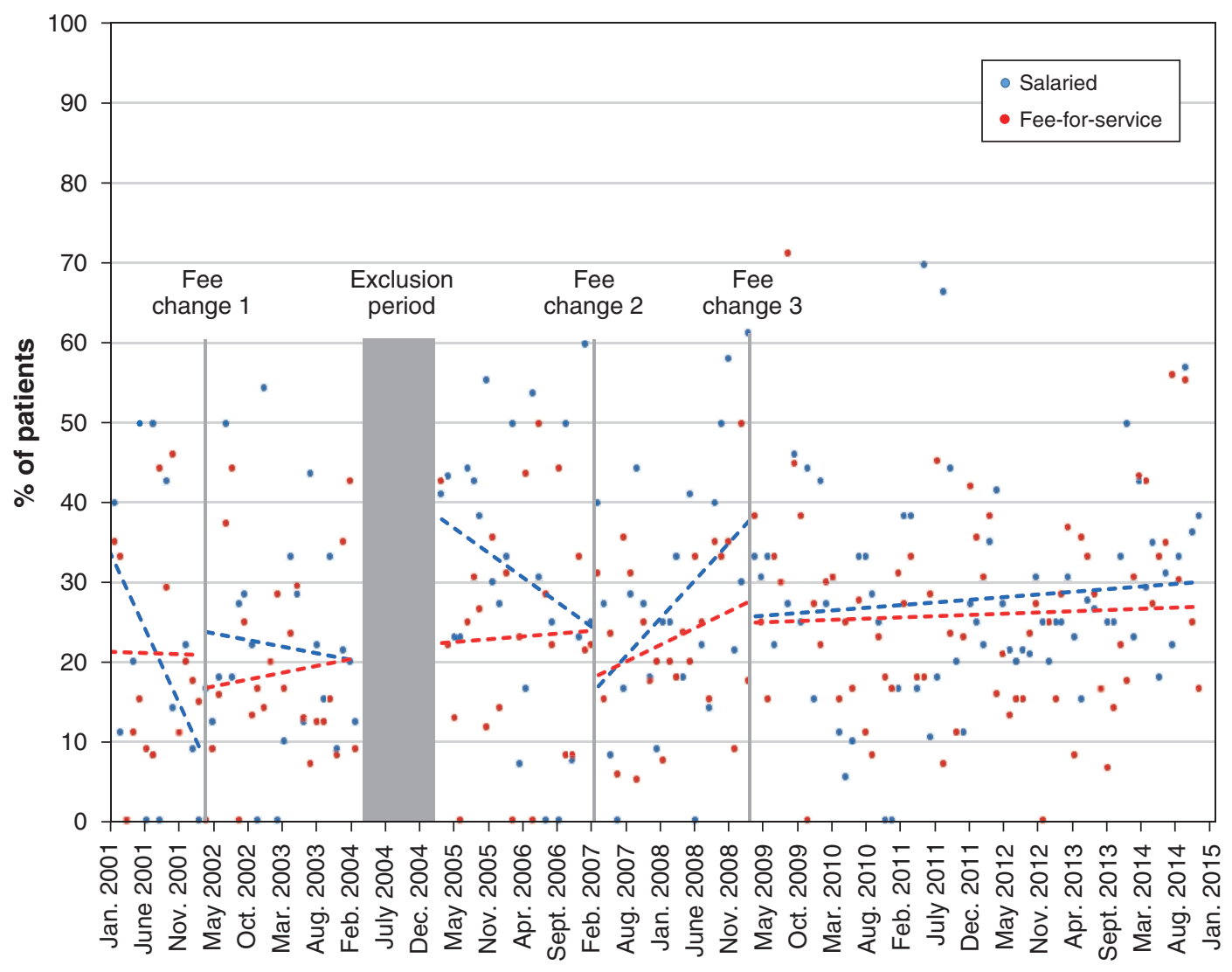

Time

Figure 3: Proportion of patients starting long-term dialysis who were receiving peritoneal dialysis at 90 days in each month. For illustrative purposes, separate dashed regression lines for the fee-for-service and salaried groups before and after each fee change are displayed on top of the raw data.

This is not to say that remuneration does not affect physician behaviour in nephrology and other medical specialties. The 2004 US Medicare reimbursement reform, which incentivized hemodialysis through the tiered fee-for-service system, was associated with an increase in the frequency of physician visits for patients receiving hemodialysis and has been associated with small but statistically significant changes in outcomes, including reduced hospital admissions for fluid overload and overall mortality. ${ }^{28-30}$ There is also evidence that physician remuneration may affect the rates of obstetrical and cardiac procedures. ${ }^{31,32}$ The authors of a review and economic analysis of the impact of financial incentives on medical treatment concluded that physicians do increase health care supply as payment increases but that the response is stronger with elective procedures than with less-discretionary services, ${ }^{33}$ such as dialysis. Therefore, it is possible that, at the individual patient level, there are stronger factors driving dialysis modality selection that lead both physicians and patients to a decision with little perceived ambiguity, thus reducing the price elasticity.

\section{Limitations}

Our study has several strengths, including the use of population-level data, robust complementary analyses and use of a control group. Although we expect that our results are generalizable to other Canadian provinces with similar nephrologist payment policies, not-for-profit dialysis facilities and independent fee-for-service physicians, the factors driving dialysis modality selection may be different in for-profit dialysis facilities, where facility-level reimbursement has been shown to influence peritoneal dialysis rates. ${ }^{12,13}$

We assessed our outcomes using health administrative data and clinical databases, and misclassification is possible. Furthermore, the study was not randomized, and there were some differences in baseline characteristics between groups and within groups before and after a fee change, although we controlled for these in our adjusted individual patient-level analysis. Our wide CIs reflect the fact that this study had inadequate power to detect small but potentially important effects of fee changes on peritoneal dialysis use. Furthermore, despite the large number of patients, there were only 21 and 


\begin{tabular}{|c|c|c|c|}
\hline \multirow[b]{2}{*}{ Model† } & \multicolumn{2}{|c|}{ OR } & \multirow[b]{2}{*}{$\begin{array}{l}\text { Differences-in-differences } \\
\text { estimator }(95 \% \mathrm{Cl}) \ddagger\end{array}$} \\
\hline & $\begin{array}{l}\text { Fee-for-service } \\
\text { post-pre }\end{array}$ & Salaried post-pre & \\
\hline \multicolumn{4}{|c|}{ Fee change 1 (Apr. 1, 2002) } \\
\hline Unadjusted & 0.81 & 1.12 & $0.72(0.35-1.48)$ \\
\hline Adjusted§ & 0.83 & 0.94 & $0.89(0.44-1.81)$ \\
\hline \multicolumn{4}{|c|}{ Fee change 2 (Apr. 1, 2007) } \\
\hline Unadjusted & 1.10 & 0.88 & $1.24(0.86-1.80)$ \\
\hline Adjusted§ & 1.03 & 0.89 & $1.15(0.73-1.83)$ \\
\hline \multicolumn{4}{|c|}{ Fee change 3 (Apr. 1, 2009) } \\
\hline Unadjusted & 1.17 & 0.90 & $1.31(0.87-1.80)$ \\
\hline Adjusted§ & 1.31 & 0.87 & $1.52(0.96-2.40)$ \\
\hline \multicolumn{4}{|c|}{$\begin{array}{l}\text { Note: } \mathrm{Cl}=\text { confidence interval, } \mathrm{OR}=\text { odds ratio. } \\
\text { *The same subset of data served for the periods after fee change } 2 \text { and before fee change 3. } \\
\text { †Fee change 1: weekly fee-for-service remuneration for peritoneal dialysis introduced at } \$ 32.16 \text {; fee change 2: weekly } \\
\text { fee-for-service remuneration for peritoneal dialysis increased from } \$ 49.15 \text { to } \$ 70.94 \text {; fee change 3: weekly fee-for-service } \\
\text { remuneration for all patients receiving dialysis } \$ 135 \text {. } \\
\text { fThe differences-in-differences estimator is the odds ratio for peritoneal dialysis use in the fee-for-service group after versus } \\
\text { before a fee change, divided by the odds ratio for peritoneal dialysis use in the salaried group after versus before a fee change. } \\
\text { §Adjusted model controlled for patient-level covariates shown in Tables } 1 \text { and } 2 \text {. }\end{array}$} \\
\hline
\end{tabular}

20 fee-for-service nephrologists in study periods 1 and 2, respectively. It is possible that a larger number of nephrologists representing a spectrum of behaviour toward incentives is required to detect the true effect of increasing remuneration.

Finally, the actual remuneration for a patient receiving hemodialysis is more complex than billing codes. Payment for hemodialysis is directed to 1 rounding nephrologist who covers all patients in the unit (including those of his or her colleagues), with each nephrologist providing different amounts of rotating coverage. Thus, the perceived financial incentive (or disincentive) of dialysis modality is difficult to measure and also involves group dynamics. It is possible that our study was underpowered to detect small differences in peritoneal dialysis use. As such, researchers in other jurisdictions could conduct similar natural experiments when undergoing changes in physician remuneration for dialysis or other procedures to clarify the circumstances in which changes in fee codes might be expected to lead to changes in physician behaviour.

\section{Conclusion}

Increasing payment to fee-for-service nephrologists for providing care to patients using peritoneal dialysis was not associated with a statistically significant increase in the use of peritoneal dialysis 90 days after initiation of long-term dialysis. Policy-level interventions aimed at increasing peritoneal dialysis use should explore interventions and strategies to address other barriers to the use of this modality or consider studying the value of larger financial incentives to encourage physicians to prescribe peritoneal dialysis as their method of choice for renal replacement therapy.

\section{References}

1. Korevaar JC, Feith GW, Dekker FW, et al. Effect of starting with hemodialysis compared with peritoneal dialysis in patients new on dialysis treatment: a randomized controlled trial. Kidney Int 2003;64:2222-8.

2. Yeates $\mathrm{K}, \mathrm{Zhu} \mathrm{N}$, Vonesh $\mathrm{E}$, et al. Hemodialysis and peritoneal dialysis are associated with similar outcomes for end-stage renal disease treatment in Canada. Nephrol Dial Transplant 2012;27:3568-75.

3. Waldum-Grevbo B, Leivestad T, Reisaeter AV, et al. Impact of initial dialysis modality on mortality: a propensity-matched study. BMC Nephrol 2015;16:179.

4. van de Luijtgaarden MW, Noordzij M, Stel VS, et al. Effects of comorbid and demographic factors on dialysis modality choice and related patient survival in Europe. Nephrol Dial Transplant 2011;26:2940-7.

5. Liu FX, Gao X, Inglese G, et al. A global overview of the impact of peritoneal dialysis first or favored policies: an opinion. Perit Dial Int 2015;35:406-20.

6. Klarenbach SW, Tonelli M, Chui B, et al. Economic evaluation of dialysis therapies. Nat Rev Nephrol 2014;10:644-52.

7. Lameire N, Van Biesen W. Epidemiology of peritoneal dialysis: a story of believers and nonbelievers. Nat Rev Nephrol 2010;6:75-82.

8. Kaplan AA. Peritoneal dialysis or hemodialysis: present and future trends in the United States. Contrib Nephrol 2017;189:61-4.

9. Sood MM, Tangri N, Hiebert B, et al. Geographic and facility-level variation in the use of peritoneal dialysis in Canada: a cohort study. CMA7 Open 2014;2:E36-44.

10. Oreopoulos DG, Coleman S, Doyle E. Reversing the decreasing peritoneal dialysis (PD) trend in Ontario: a government initiative to increase PD use in Ontario to $30 \%$ by 2010. Perit Dial Int 2007;27:489-95.

11. Just PM, de Charro FT, Tschosik EA, et al. Reimbursement and economic factors influencing dialysis modality choice around the world. Nephrol Dial Transplant 2008;23:2365-73.

12. Hirth RA, Turenne MN, Wheeler JR, et al. The initial impact of Medicare's new prospective payment system for kidney dialysis. Am 7 Kidney Dis 2013;62:662-9.

13. Brunelli SM, Monda KL, Burkart JM, et al. Early trends from the Study to Evaluate the Prospective Payment System Impact on Small Dialysis Organizations (STEPPS). Am 7 Kidney Dis 2013;61:947-56.

14. Golper TA. The possible impact of the US prospective payment system ("bundle") on the growth of peritoneal dialysis. Perit Dial Int 2013;33:596-9.

15. Vanholder R, Davenport A, Hannedouche T, et al. Reimbursement of dialysis: a comparison of seven countries. 7 Am Soc Nephrol 2012;23:1291-8.

16. Chow KM, Li PK. Dialysis: Choice of dialysis - what to do with economic incentives. Nat Rev Nephrol 2012;8:495-6.

17. Erickson KF, Winkelmayer WC, Chertow GMBJ. Effects of physician payment reform on provision of home dialysis. Am 7 Manag Care 2016;22:e215-23.

18. Mendelssohn DC, Langlois N, Blake PG. Peritoneal dialysis in Ontario: a natural experiment in physician reimbursement methodology. Perit Dial Int 2004; 24:531-7. 
19. Manns BJ, Mortis GP, Taub KJ, et al. The Southern Alberta Renal Program database: a prototype for patient management and research initiatives. Clin Invest Med 2001;24:164-70.

20. Hemmelgarn BR, Clement F, Manns BJ, et al. Overview of the Alberta Kidney Disease Network. BMC Nephrol 2009;10:30.

21. Chong CC, Tam-Tham H, Hemmelgarn BR, et al. Trends in the management of patients with kidney failure in Alberta, Canada (2004-2013). Can 7 Kidney Health Dis 2017;4:2054358117698668.

22. Tonelli M, Wiebe N, Fortin M, et al. Methods for identifying 30 chronic conditions: application to administrative data. BMC Med Inform Decis Mak 2015;15:31.

23. 2001 census of population. Ottawa: Statistics Canada; 2001. Available: https:// www12.statcan.gc.ca/english/census01/home/index.cfm (accessed 2019 Dec. 19).

24. 2006 census of population. Ottawa: Statistics Canada; 2006. Available: https:// www12.statcan.gc.ca/census-recensement/2006/ref/about-apropos/version-eng. cfm (accessed 2019 Dec. 19).

25. 2011 National Housebold Survey questionnaires and guides. Ottawa: Statistics Canada; 2011. Available: https://www12.statcan.gc.ca/nhs-enm/2011/ref/about -apropos/ques_guide-eng.cfm (accessed 2019 Dec. 19).

26. Postal Code Conversion File (PCCF), reference guide. Ottawa: Statistics Canada; 2017. Available: https://www150.statcan.gc.ca/n1/en/catalogue/92-154-G (accessed 2019 Dec. 19).

27. Hubbard AE, Ahern J, Fleischer NL, et al. To GEE or not to GEE: comparing population average and mixed models for estimating the associations between neighborhood risk factors and health. Epidemiology 2010;21:467-74.

28. Mentari EK, DeOreo PB, O'Connor AS, et al. Changes in Medicare reimbursement and patient-nephrologist visits, quality of care, and health-related quality of life. Am 7 Kidney Dis 2005;46:621-7.

29. Erickson KF, Winkelmayer WC, Chertow GM, et al. Medicare reimbursement reform for provider visits and health outcomes in patients on hemodialysis. Forum Health Econ Policy 2014;17:53-77.

30. Erickson KF, Winkelmayer WC, Chertow GM, et al. Hemodialysis hospitalizations and readmissions: the effects of payment reform. Am $\mathcal{7}$ Kidney Dis 2017;69:237-46.

31. Yip WC. Physician response to Medicare fee reductions: changes in the volume of coronary artery bypass graft (CABG) surgeries in the Medicare and private sectors. 7 Health Econ 1998;17:675-99.

32. Coey D. Physicians' financial incentives and treatment choices in heart attack management. Quant Econ 2015;6:703-48.

33. Clemens J, Gottlieb JD. Do physicians' financial incentives affect medical treatment and patient health? Am Econ Rev 2014;104:1320-49.
Affiliations: Department of Internal Medicine (Trachtenberg), University of Manitoba, Winnipeg, Man.; Departments of Community Health Sciences (Quinn, Ma, Hemmelgarn, Tonelli, Faris, Weaver, Au, Zhang, Manns) and Medicine (Hemmelgarn, Tonelli, Manns), and Libin Cardiovascular Institute of Alberta and O'Brien Institute for Public Health (Hemmelgarn, Tonelli, Manns), Cumming School of Medicine, University of Calgary, Calgary, Alta.; Department of Medicine (Klarenbach), University of Alberta, Edmonton, Alta.; Alberta Health Services (Faris), Calgary, Alta.

Contributors: Aaron Trachtenberg and Braden Manns were responsible for project administration. Aaron Trachtenberg, Amity Quinn, Scott Klarenbach, Peter Faris, Jianguo Zhang and Braden Manns conceived the study. Aaron Trachtenberg, Zhihai Ma, Peter Faris and Jianguo Zhang designed the study. Amity Quinn, Zhihai Ma, Robert Weaver and Flora Au acquired the data. Zhihai Ma, Robert Weaver and Flora $\mathrm{Au}$ analyzed the data. Brenda Hemmelgarn and Marcello Tonelli were responsible for funding acquisition and resources. Aaron Trachtenberg drafted the manuscript. All of the authors interpreted the data, revised the manuscript critically for important intellectual content, approved the final version to be published and agreed to be accountable for all aspects of the work.

Funding: This study was funded by Canadian Institutes of Health Research Foundation grant 201509FON-353640 to Braden Manns, a Banting Postdoctoral Fellowship to Amity Quinn and an Alberta Innovates Collaborative Research \& Innovation Opportunity Team Grant.

Disclaimer: This study is based in part on data provided by Alberta Health. The interpretation and conclusions contained herein are those of the authors and do not necessarily represent the views of the Government of Alberta. Neither the Government of Alberta nor Alberta Health expresses any opinion in relation to this study.

Supplemental information: For reviewer comments and the original submission of this manuscript, please see www.cmajopen.ca/content/8/1/ E96/supp1/DC1. 